\title{
Aetiology and Management of Epistaxis - A Prospective Clinical Study
}

Research Article

Bhadouriya $\mathrm{SS}^{1 *}$, Raghuvanshi $\mathrm{S}^{2}$

${ }^{1}$ Assistant Professor, Department of E.N.T and Head \& Neck Surgery, School of Medical Science \& Research, Greater Noida, 201306, India.

${ }^{2}$ Associate professor, Department of E.N.T and Head \& Neck Surgery, L.N. Medical College, Bhopal, 462007, India.

\section{Abstract}

Objective : Epistaxis is a common clinical problem and is an uncomfortable experience that can cause great apprehension and anxiety in patients. Most nose bleed are benign, spontaneous and self-limiting. Epistaxis can range from minor bleed to profuse bleed that can be life threatening and warrant urgent medical attention. By this means it becomes necessary to study aetiology, age and sex incidence, seasonal variation, site and management of epistaxis.

Methods : This prospective study was carried out in Department of Otorhinolaryngology, School of Medical Sciences and Research, Greater Noida from January 2013 to June 2014. The study subjects included 100 patients who presented with epistaxis during the period under study.

Results : The mean age of patients were 30.44 \pm 19.08 (SD) years and male to female ratio was 3:1. Epistaxis was more common during hot dry months and dry cold winter months. Trauma to the nose caused epistaxis in $35 \%$ of case. Neoplasms of nose, paranasal sinuses and nasopharynx were observed to be responsible for epistaxis in $13 \%$ of cases. Acute and chronic inflammatory conditions of nose were responsible for epistaxis in 13\% of cases. High blood pressure was found in $10 \%$ of cases. In 7\% of the cases, epistaxis was idiopathic. Anterior bleed was present in $69 \%$ of cases while posterior nasal bleed was seen in $34 \%$ of cases, in $12 \%$ cases site is undetermined.

Conclusion : $79 \%$ cases treated successfully with conservative approach while $21 \%$ cases required surgical intervention. In this study conservative treatment was found effective in most cases.

Keywords: Epistaxis; Aetiology; Trauma; Hypertension; Idiopathic; Nasal packing.

\section{Introduction}

Epistaxis is a symptom of various conditions and is a common occurrence. The term epistaxis is Latin, derived from the Greek word 'EPISTAZEIN' which means to flow, drop by drop [1]. Vogel in 1764 suggested that this term should be used to denote nasal bleeding only. The condition is self-limiting and most people do not go to the hospital. True incidence is therefore unknown but epistaxis is estimated to occur in $60 \%$ of individual's worldwide [2] and $6 \%$ of them seek medical attention [3]. Incidence from most studies ranges from $10 \%$ to $15 \%$ [4,5]. Epistaxis has been described as accounting for $33 \%$ of ear, nose and throat emergency admission within the United Kingdom and median age of admission was reported as 70 years [6]. A slight male preponderance with $55 \%$ male and $45 \%$ female has been reported $[7,8]$. Epistaxis is rare in neonates but common among children and young adults, and again common in the sixth decade giving a bimodal age presentation $[3,6,9]$. Epistaxis as seasonal variation can occurs more frequently during the dry hot and cold winter months [10]. Epistaxis is divided into anterior and posterior epistaxis depending on the site of origin [6]. Anterior nose bleeds arise from the Little's area and common in children and young adults. Posterior nose bleed arise from damage to the posterior nasal septal artery and common after 40 years of age $[11,12]$. Anterior epistaxis is far more common than posterior epistaxis, accounting for more than $80 \%$ of cases $[11,13]$. The causes and course of epistaxis is probably multi-factorial. Causes of epistaxis

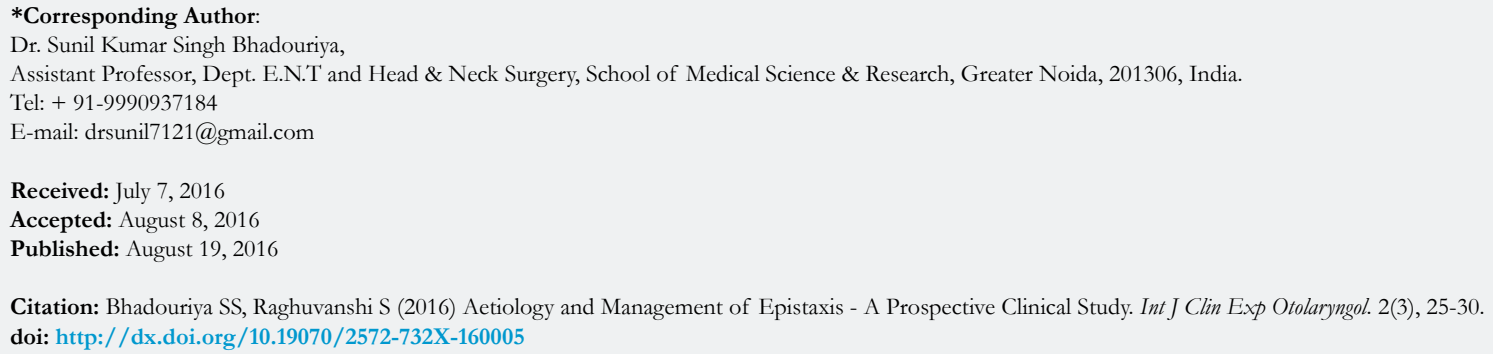

Copyright: Bhadouriya SS ${ }^{\circ}$ 2016. This is an open-access article distributed under the terms of the Creative Commons Attribution License, which permits unrestricted use, distribution and reproduction in any medium, provided the original author and source are credited. 
can be categorized in many ways but broadly into local and general causes. Aetiology of epistaxis has been reported to vary according to age and anatomical location $[11,14]$. Local causes ranges from trauma, infection, neoplasms of nasal cavity paranasal sinuses and nasopharynx to rare congenital causes. While general causes includes hypertension, blood and blood vessel disorders, bleeding disorders, to liver and renal disorders. Epistaxis due to trauma is more common in younger individuals and is most often due to digital trauma, facial injury, or a foreign body in the nasal cavity $[12,14]$. Non traumatic epistaxis is more common in older patients. Epistaxis that occurs in children is usually mild and originates in the anterior nose. Epistaxis that occurs in older individuals is likely to be severe and originates posteriorly [15]. Epistaxis can also occur without any apparent reason or cause in $80 \%-90 \%$ of cases $[11,14]$. The treatment of epistaxis requires a systematic approach and options vary according to the cause, location, and severity of the haemorrhage [11-13,15]. Both conservative and surgical treatment modalities have been used in the treatment of epistaxis $[12,16]$. Most of the underlying causes of epistaxis are preventable $[14,15]$. A fine understanding of the causes, treatment and outcome of these patients is important for establishment of preventive strategies as well as treatment guidelines $[13,14]$. Broad availability of endoscopic equipment is shifting management toward targeting the bleeding point. This shift may have a significant impact on decreasing length of stay and blood transfusion rates. In majority of cases of epistaxis only conservative treatment such as local pressure, vasoconstrictor drugs, anterior and posterior nasal packing are needed. Epistaxis refractory to conservative treatment can be treated surgically by ligating sphenopalatine artery, internal maxillary artery, external carotid artery and ethmoidal arteries. With the emergence of interventional radiology these cases can also be managed by embolizing the bleeding vessel. Sokoloff was the first one who described the use of embolization in epistaxis. Embolization is not a completely risk free procedure and has potential for serious complications such as soft tissue necrosis, facial nerve paralysis and blindness.

\section{Material and Methods}

\section{Study Design}

This prospective study was carried out in Department of Otorhinolaryngology, School of Medical Sciences and Research, Greater Noida from January 2013 to June 2014.

\section{Study Population: Inclusion \& Exclusion Criteria}

The study subjects included 100 patients who presented with epistaxis during the period under study. The patients from the emergency department, ENT OPD, ENT IPD and referral from other departments were included in the study. Patients without consent were excluded from the study.

\section{Methodology}

Detailed clinical history was taken. General physical examination of the patients with attention to pulse, temperature, blood pressure, pallor and subcutaneous bleeding was done. Systemic examination was done in detail with special attention towards liver and spleen enlargement. Detailed ENT examination was done. Complete blood chemistry and coagulation profile were done in each and every case. Histopathological examination and radiological investigations were done when necessary. In addition to above investigations, routine urine examination, blood sugar, blood urea, serum creatinine, and E.C.G. were done in appropriate cases.

\section{Statistical Study}

Data was collected using a proforma and data collected included patients demographics, etiology, site and management modality. Data collected were entered in SPSS version 16 for analysis. Data were presented as mean plus or minus standard deviation for continuous variables and number of cases was used for categorical ones.

\section{Ethical Aspects}

The study protocol was approved by Institute Ethical Committee. Informed and written consent were taken from all the patients included in the study.

\section{Results}

There were 100 patients of age 1 to 80 years with mean age of $30.44 \pm 19.08$ (SD) years. Figure 1 is showing two peaks where incidence was maximum. One is between age group 11-20 years ( $25 \%$ cases) and another age group is $41-50$ years (19\% cases).

In the present study $75 \%$ of the cases were males and rest $25 \%$ were females. The male to female ratio is approximately $3: 1$. Table 1 shows that males are more often affected than females.

Figure 2 Shows maximum number of patients presented with epistaxis in the month of June (16 cases), followed by the month of March (11 cases) and October (10 cases) respectively.

In this present study $54(54 \%)$ had anterior bleeding and $19(19 \%)$ had posterior bleeding. While in $12 \%$ of cases site of bleeding could not be determined. 15 (15\%) cases had both anterior and posterior bleeding. Bleeding was from anterior part of septum in $44 \%$ of cases and from posterior part of septum in $15 \%$ of cases Figure 3.

Table 2 shows results of histopathological examination performed in 17 cases for growth in patients who presented with epistaxis.

Trauma to the nose caused epistaxis in $35 \%$ of cases; in these $13 \%$ cases were due to assault, $20 \%$ cases were due to road side accident, $2 \%$ cases due to nose picking. Inflammatory causes were responsible for epistaxis in $13 \%$ of cases. Anatomic deformity that is deviated nasal septum was observed to be responsible for epistaxis in $5 \%$ cases. Neoplasms were observed to be responsible for epistaxis in $13 \%$ of cases; $10 \%$ cases were of benign neoplasms and $3 \%$ were due to malignant neoplasms. Foreign bodies were responsible for epistaxis in $6 \%$ case. Infestation with maggots was found as a cause for epistaxis in $7 \%$ of cases. Among systemic causes, hypertension accounted for epistaxis in 10\% of cases. Bleeding disorders were responsible in $2 \%$ of cases and drugs were found to be responsible for epistaxis in $2 \%$ of cases. $7 \%$ of the cases were labeled as idiopathic. Figure 4 is showing aetiology 
Figure. 1. Age Wise Incidence $(n=100)$

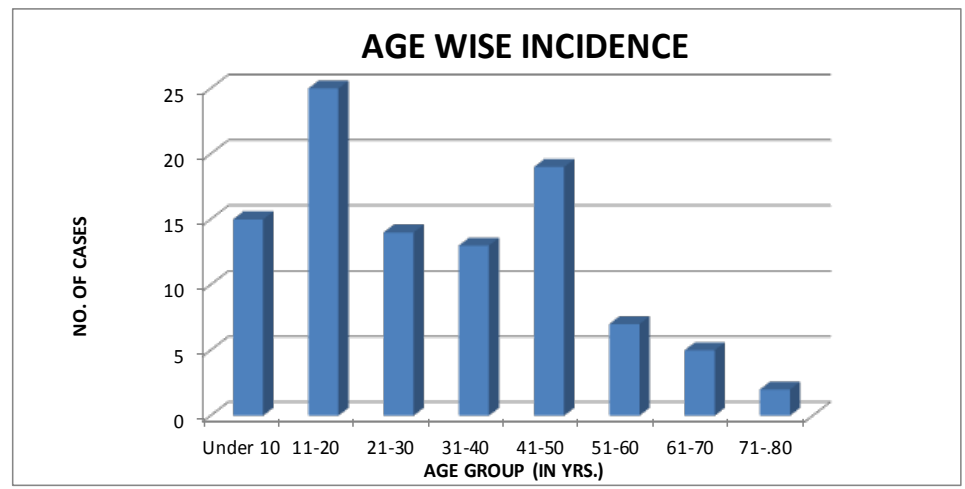

Table 1. Sex wise incidence

\begin{tabular}{|c|c|c|c|}
\hline S.No. & Sex & No. of cases & $\%$ \\
\hline 1 & Male $:$ Female & $75: 25: 00$ & $75: 25: 00$ \\
\hline
\end{tabular}

Figure. 2. Seasonal Variation

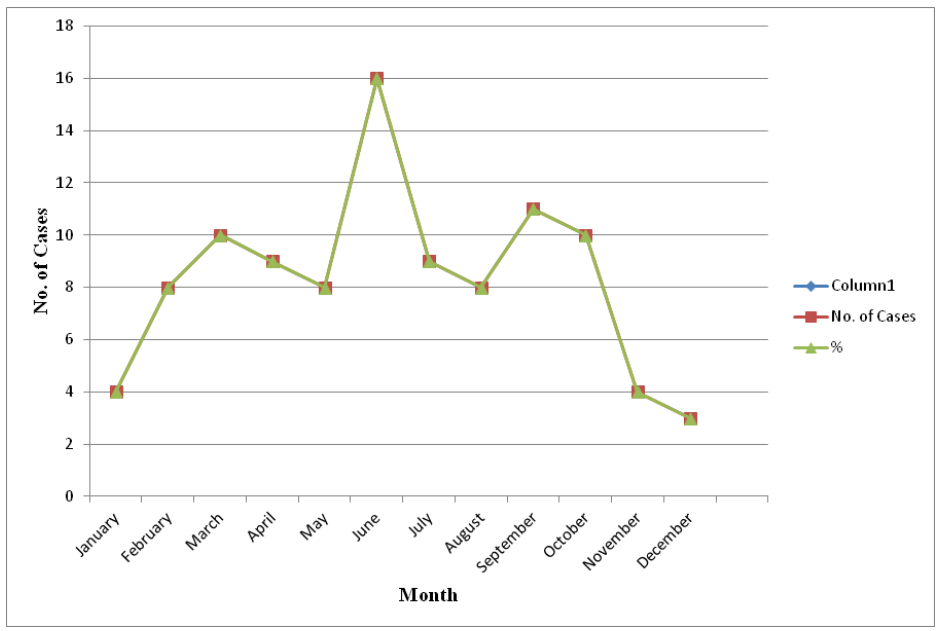

Figure. 3. Site of Bleeding

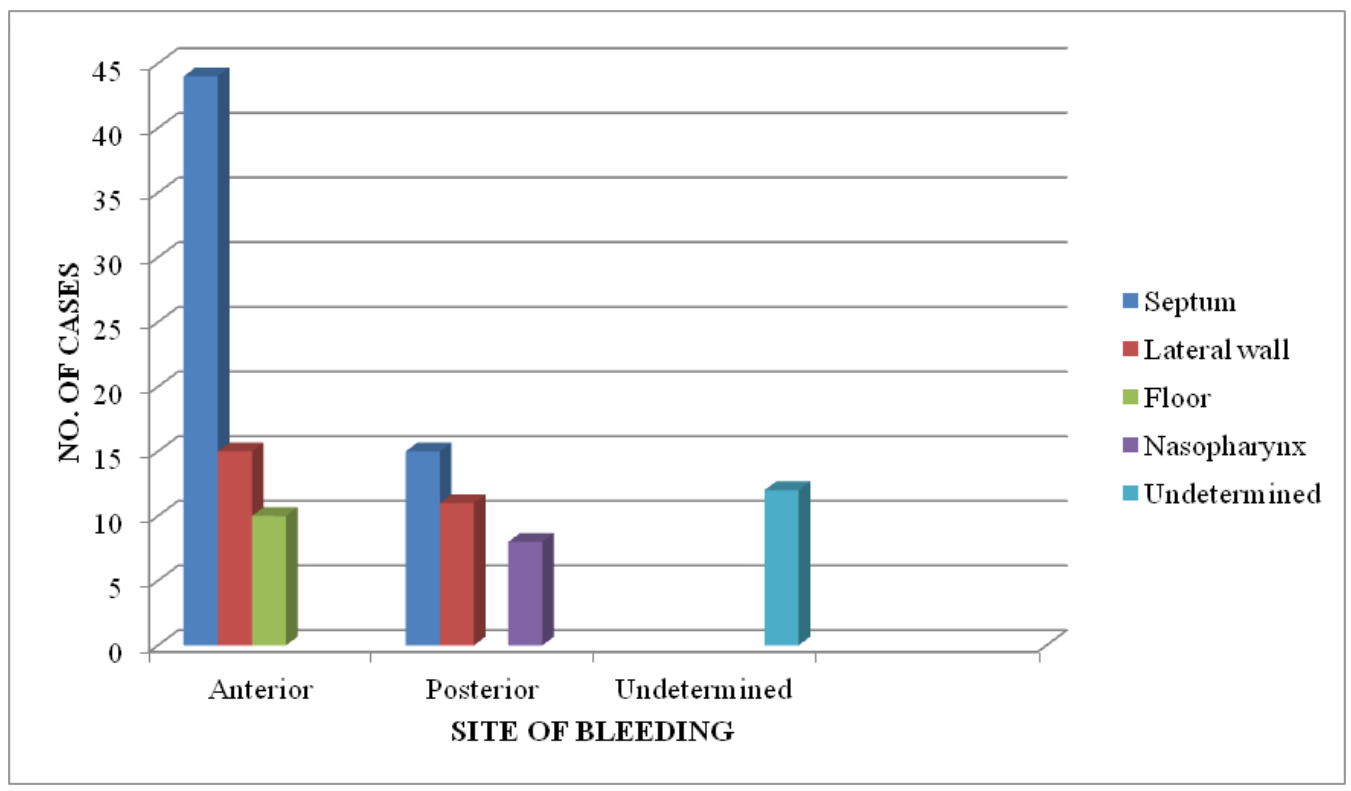


Table 2. Histopathological examination

\begin{tabular}{|c|c|c|c|}
\hline S.No. & Histopathology & No. of cases & $\%$ \\
\hline 1 & Rhinosporidiosis & 4 & 4 \\
\hline 2 & Angiofibroma & 4 & 4 \\
\hline 3 & Adenocarcinoma & 1 & 1 \\
\hline 4 & Angioma & 3 & 3 \\
\hline 5 & Nasopharyngeal Ca & 3 & 1 \\
\hline 6 & Inverted papilloma & 1 & 3 \\
\hline 7 & Squamous cell carcinoma & & 1 \\
\hline
\end{tabular}

Figure.4. Aetiology of Epistaxis

\section{AETIOLOGY OF EPISTAXIS}

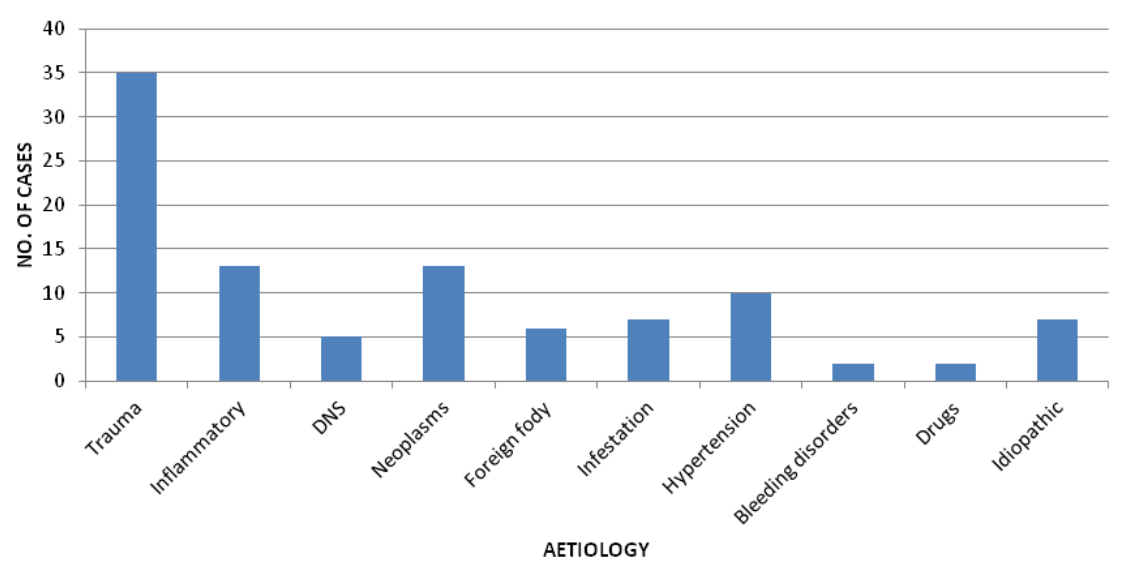

Table.3. Various treatments applied: Nonsurgical (79)

\begin{tabular}{|c|c|}
\hline Treatment & No.of patient $(\mathrm{n}=79)$ Percentage \\
\hline Chemical cauterization & 2121 \\
\hline Electric cauterization & 33 \\
\hline Anterior nasal packing & 4040 \\
\hline Posterior nasal packing & 44 \\
\hline Foleys catheter as post packing & 66 \\
\hline Blood transfusion & 55 \\
\hline
\end{tabular}

Table.4. Surgical (21cases)

\begin{tabular}{|c|c|c|}
\hline Treatment & No.of patient $(\mathrm{n}=21)$ & Percentage \\
\hline Septal surgery & 5 & 5 \\
\hline Sinus surgery & 2 & 2 \\
\hline Lateral rhinotomy & 4 & 4 \\
\hline Trans palatine & 4 & 4 \\
\hline Arterial ligation & 0 & 0 \\
\hline Excision of mass with & 3 & 3 \\
\hline endoscopic cauterization & & 0 \\
\hline Angiography/embolization & 0 & 3 \\
\hline Endoscopic excision & 3 & 0 \\
\hline Endoscopic ligation & 0 & \\
\hline
\end{tabular}


of epistaxis.

In present study out of 100 cases 79 responded to conservative or nonsurgical treatment, which included anterior nasal packing (40\%), posterior nasal packing $(4 \%)$, chemical cauterization $(21 \%)$, electric cauterization( $3 \%$, Foleys catheter as a posterior nasal packing $(6 \%)$ and blood transfusion $(5 \%)$. Table 3 is showing nonsurgical treatment applied.

In 21 cases surgical procedures were performed, which include septal surgery (5\%cases), sinus surgery (2\%), Endoscopic excision of $\operatorname{mass}(3 \%)$, Excision of mass with endoscopic cauterization $(3 \%)$, lateral rhinotomy (4\%), trans palatine approach (4\%) with no mortality (Table 4).

\section{Discussion}

In the present study, two peaks were observed one is between $11-20$ years of age (25\% cases) and other between $41-50$ years of age (19\% cases). Minimum numbers of cases ( $2 \%$ cases) were between 71-80 years of age. Varshney et al., in their retrospective study mentioned that the mean age of presentation was 47.8 years and the maximum patients were in the age group of 40-50 years and minimum were in the age group of $71-80$ years [3]. Their observation to some extent also corresponds with present study. Arshad et al., in their study of epistaxis in 109 patients mentioned that the mean age of presentation was $35.061 \pm 9$ years and maximum cases were in the age group of 20-30 years [17].

In the present study males are more often affected than females. In the present study $75 \%$ of the cases were males and rest $25 \%$ were females. Varshney et al. observed in their study that, males were affected more frequently than females [3]. Arshad et al., in their study found 76 males and 33 females with male to female ratio of 2.4:1 [17]. Chaiyasate $S$. et al. reviewed 55 cases and mentioned that 41 cases were males and 14 were females [18].

In present study, two peaks were observed, one in the months of March to June (43\% cases) and other from October to February (29\% cases). Therefore it can be said that epistaxis is more common during dry hot summer months and dry cold winter months. The incidence of epistaxis was low during rainy season. Varshney et al. mentioned that the number of cases of epistaxis was more in autumn and winter months and low during MayAugust [3]. The present study is in accordance with the studies done by different authors regarding seasonal variation in cases of epistaxis.

In present study, $50 \%$ case of epistaxis had recurrent episodes of epistaxis. In a retrospective study done by Victor Abrich et al., there were 461 cases with at least 2 episodes of spontaneous epistaxis within 3 years and 912 controls with only one episode in the same time frame [19]. Yuji Ando et al., in their study of 299 patients in Tokyo Japan found $32(10.7 \%)$ patients with recurrent epistaxis [20].

In the present study bleeding was unilateral in $85 \%$ cases and bilateral in 15\% cases. $69(69 \%)$ had anterior bleeding and $34(34 \%)$ had posterior bleeding. while in $12 \%$ of cases site of bleeding could not be determined. $15(15 \%)$ cases had both anterior and posterior bleeding. Arshad et al. in their study of epistaxis in 109 patient found Sixty-six patients $(60.55 \%)$ had anterior and 25 $(22.93 \%)$ had posterior bleeding; while in remaining bleeding site could not be identified [17]. Varshney et al. in their study of 88 patients found 50 cases had bleeding from septum, out of which in 36 cases it was from anterior part and in remaining 14 cases bleeding was from the posterior part of the septum. In 23 cases $(26 \%)$ the bleeding was from the lateral wall [3].

In this study, trauma to the nose caused epistaxis in $35 \%$ cases. Out of $35 \%$ cases, $13 \%$ cases were due to assault, $20 \%$ cases were due to road side accident and $2 \%$ cases due to nose picking. Razdan et al., in their study of epistaxis in 300 patients stated that traumatic epistaxis was the commonest cause $33 \%$ among outdoor patients [21]. Observation made by above mentioned authors goes in accordance with current study. Many studies reported trauma as the main cause of epistaxis $[22,23]$. Most western literature cites idiopathic causes as the commonest followed by trauma $[4,5]$.

In present study, neoplasms of nose, paranasal sinuses and nasopharynx were observed to be responsible for epistaxis in $13 \%$ of cases; $10 \%$ cases were of benign neoplasms and 3\% were due to malignant neoplasms. Varshney et al., noted neoplasia as a reason for epistaxis in $1.14 \%$ cases [3]. The observation of current study goes against that made by various authors, as we noted fairly large number of cases presenting with epistaxis had tumors of nose, paranasal sinuses and nasopharynx.

Acute and chronic inflammatory conditions of nose, in present study were responsible for epistaxis in $13 \%$ of cases. Rhinosporidiosis was responsible for epistaxis in $4 \%$ cases, $3 \%$ of cases were each of nasal vestibulitis and atrophic rhinitis, and $2 \%$ cases of chronic maxillary sinusitis and 1\% tuberculosis of nose. Varshney et al., observed infection as a cause for epistaxis in $19.32 \%$ cases [3].

In present study, anatomic deformity that is deviated nasal septum was observed to be responsible for epistaxis in 5\% cases, nonhygroscopic foreign bodies were observed to be responsible in $6 \%$ cases and infestation with maggots was found as a cause for epistaxis in $7 \%$ of cases. Most of the case of infestation with maggots reported in the month of October and November.

Among systemic causes, hypertension accounted for epistaxis in $10 \%$ of cases. Most of the cases presenting with hypertension were males, between $45-80$ years of age. Razdan in their study stated that hypertension was the most common systemic cause among indoor patients $(62.2 \%)$. Holger Juselius observed hypertension in $47.3 \%$ cases of epistaxis. These observations are in contrast with the present study. Many studies have shown hypertension as a common cause of epistaxis $[23,25]$.

In present study drug intake was found to be responsible for epistaxis in $2 \%$ cases. These cases had a definite history of drug intake prior to epistaxis. Bleeding disorders accounted for epistaxis in $2 \%$ of cases in the present study. Varshney et al., reported that in $4.55 \%$ cases bleeding diathesis including liver diseases was responsible for epistaxis [3].

In present study, in $7 \%$ of the cases, in spite of detailed history taking through clinical examination and investigations no obvious organic cause could be found and therefore, these cases were 
labeled as idiopathic. Varshney et al. reported 35.23\% cases with idiopathic epistaxis. Razdan et al., in their study stated that idiopathic epistaxis contributed for $16.5 \%$ indoor and $26.1 \%$ of outdoor cases [21]. These observations are in contrast with the present study.

In this present study out of 100 cases 79 responded to conservative or nonsurgical treatment, which included anterior nasal packing (40\%), posterior nasal packing(4\%), chemical cauterization( $21 \%$ ), electric cauterization(3\%), Foleys catheter as a posterior nasal packing $(6 \%)$ and blood transfusion(5\%). In 21 cases surgical procedures were performed, which include septal surgery (5\%cases), sinus surgery ( $2 \%$, Endoscopic excision of mass $(3 \%)$, Excision of mass with endoscopic cauterization( $3 \%$, lateral rhinotomy (4\%), trans palatine approach (4\%) with no mortality. Varshney et al., treated $70.45 \%$ of patients successfully by nonsurgical or non-interventional approaches. Conservative treatment strategies failed only in $29.55 \%$, and these patients required surgical or interventional approaches [3]. In a study done by Arshad et al., $81.66 \%$ patients responded to conservative or nonsurgical treatment. In $18.35 \%$ patients some surgical procedures were performed [17].

\section{Conclusion}

Epistaxis is a common clinical condition and requires prompt treatment to reduce morbidity and mortality. Trauma to nose appeared as the most common cause for epistaxis in this study. History of recurrence of epistaxis was mostly associated with presence of tumour mass in nasal cavity or nasopharynx, so a through anterior and posterior rhinoscopy examination is always essential to rule out any growth. In this study most cases were successfully managed with conservative treatment and few cases required surgical treatment. Epistaxis refractory to conservative treatment can be treated either surgically or by embolization. Nonsurgical treatment is safe and cost effective and surgical treatment may not be necessary in most cases and should be the last resort.

\section{References}

[1]. Swift AC, Bleier BS, Bhalla RK, Schlosser RJ (2013) Epistaxis: etiology, investigations and management. Rhinology and skull base surgery from the lab to the operating room: an evidence based approach. Thieme medical publisher, New York, USA. 507-523.

[2]. Viehweg TL, Roberson JB, Hudson JW (2006) Epistaxis: diagnosis and treatment. J Oral Maxillofac Surgery 64(3): 511-518.

[3]. Varshney S, Saxena RK (2005) Epistaxis: a retrospective clinical study. Indian J Otolaryngol Head Neck Surg 57(2): 125-129.

[4]. Watkinson JC (1997) Epistaxis. Scott-Brown's otolaryngologyrhinology, Butterworth-Heinemann, London. 1-19.

[5]. Roland NJ, McRae RDR, McCombe AW (2001) Key topics in otolaryngology and head and neck surgery, Bios Scientific Publishers, Oxford. 72.

[6]. Walker TWM, Macfarlane TV, McGarry GW (2007) The epidemiology and chronobiology of epistaxis: an investigation of Scottish hospital admission 1995-2004. Clin Otolaryngol 32(5): 361-365.

[7]. Nnnennia CM (2004) Epistaxis in Enugu: A 9 year review. Nigerian J Otorhinolaryngol 1(1): 11-14.

[8]. Gerald WM (2008) Epistaxis: Scott-Brown's Otorhinolaryngology Head and Neck Surgery. (7th edn), Hodder Arnold. 2(13): 1596-1607.

[9]. Hussain G, Iqbal M, Shah SA, Said M, Sanaullah, Khan SA, et al., (2006) Evaluation of aetiology and efficacy of management protocol of epistaxis. J Ayub Med CollAbbottabad 18 (4): 63-66.

[10]. Tan LK, Calhoun KH (1999) Epistaxis. Med Clin North Am 83(1): 43-56.

[11]. Ciaran SH, Owain H (2009) Update on management of epistaxis. The West London Medical Journal 1(1): 33-41.

[12]. Pope LER, Hobbs CGL (2005) Epistaxis: an update on current management. Postgrad Med J 81(955): 309-314.

[13]. Nash CM, Field SMB (2008) Epidemiology of Epistaxis in a Canadian Emergency Department. Israeli Journal of Emergency Medicine 8(3): 24-28.

[14]. Pallin DJ, Chng Y, McKay MP, Emond JA, Pelletier AJ, et al., (2005) Epidemiology of epistaxis in US emergency departments, 1992 to 2001. Ann Emerg Med 46(1): 77-81.

[15]. Bernius M, Perlin D (2006) Pediatric ear, nose, and throat emergencies. Pediatr Clin North Am 53(2): 195-214.

[16]. Pond F, Sizeland A (2000) Epistaxis. Strategies for management. Aust Fam Physician 29(10): 933-938.

[17]. Arshad M, Ahmad Z, Ali L (2007) Epistaxis: an experience with over 100 cases. RMJ 32(2): 142-145.

[18]. Chaiyasate S, Roongrotwattanasiri K, Fooanan S, Sumitsawan Y (2005) Epistaxis in Chaing Mai University Hospital. J Med Assoc Thai 88(9): 12821286.

[19]. Abrich V, Brozek A, Boyle TR, Chyou PH, Yale SH (2014) Risk factors for recurrent spontaneous epistaxis. Mayo Clin Proc 89(12): 1636-1643.

[20]. Ando Y, Limura J, Arai S, Arai C, Komori M, et al., (2014) Risk factors for recurrent epistaxis: Importance of initial treatment. Auris Nasus Larynx 41(1): 41-45.

[21]. Razdan U, Zada R, Chaturvedi VN (1999) Epistaxis: Study of aetiology, site and side of bleeding. Indian J Med Sci 53(12): 545-552.

[22]. Yang WG, Tsai TR, Hung CC, Tung CC (2001) Life threatening bleeding in a facial fracture. Ann Plast Surg 46(2): 159-162.

[23]. Gilyoma GM, Chalya PL (2011) Etiological profile and treatment outcome of epistaxis at a tertiary care hospital in north western Tanzania: a prospective review of 104 cases. BMC Ear, Nose and Throat disorders 11: 8-14.

[24]. Hanif M, Rizwan M, Rabbani MZ, Chaudhari MA (2001) Common cause of epistaxis: a two years' experience at Rawalpindi general hospital. J of Surg Pakistan 6(2): 2-3.

[25]. Iseh KR, Muhammad Z (2008) Pattern of epistaxis in Sokoto, Nigeria: a review of 72 cases. Ann Afr Med 7(3): 107-111. 